\title{
A Mathematical Approach for Three Stage Flow Shop Production Schedule with Jobs in a String of Disjoint Job Block
}

\author{
Deepak Gupta \\ Department of Mathematics \\ M. M. University. Mullana \\ Ambala, India
}

\author{
Sameer Sharma \\ Department of Mathematics \\ D. A. V. College, Jalandhar \\ Punjab, India
}

\author{
Shefali Aggarwal \\ Department of Mathematics \\ M. M. University. Mullana \\ Ambala, India
}

\begin{abstract}
The aim of this paper is to introduce the concept of disjoint job blocks in $n$-jobs, three machines flow shop scheduling problem to minimize the total elapsed time and rental cost of the machines under a specified rental policy in which the processing time associated with probabilities including transportation time. A heuristic approach for flow shop with a computational algorithm to find optimal or near optimal solution is described. A computer program followed by a numerical illustration is given to justify the proposed algorithm.
\end{abstract}

\section{Keywords}

Flow Shop Scheduling; Disjoint job Block; Transportation Time; Processing TIme.

\section{INTRODUCTION}

In most real-world environments, scheduling is an ongoing reactive process where the presence of real-time information continually forces reconsideration and revision of preestablished schedules. Scheduling literature addressing three machine flow shop with multiple criteria mainly focused on two criteria, also known as bicriteria. The bicriteria scheduling problems are motivated by the fact that they are more meaningful from practical point of view. Most machine scheduling models assume that jobs are delivered instantaneously from one location to another without transportation time involved. In this paper we relax this assumption, since there are practical scheduling situations when certain times are required by jobs for their transplantation from one machine to another machine. One of the earliest results in flow shop scheduling theory is an algorithm given by Johnson [7] for scheduling jobs in a two machine flow shop to minimize the time at which all jobs are completed. Smith [12] considered minimization of mean flow time and maximum tardiness. Van Wassenhove and Gelders [16] studied minimization of maximum tardiness and mean flow time explicitly as objective. Some of the noteworthy heuristic approaches are due to Maggu \& Das [9], Sen and Gupta [14], Singh[15], Dileepan [3], Narain [10], Heydari [1], Chandramouli [2], Khodadadi [8], Pandian \& Rajendran [11] by considering various parameters. Heydari [1] dealt with a flow shop scheduling problem where the jobs are processed in two disjoint job blocks in a string consists of one block in which order of jobs is fixed \& other block in which order of job is arbitrary.
Gupta \& Sharma [5] studied bicriteria in $\mathrm{n} \times 3$ flow shop scheduling under specified rental policy, processing time associated with probabilities including transportation time and job block criteria. We have made an attempt to extend the work by introducing the jobs in a string of disjoint job blocks. The paper considers a more practical scheduling situation in which certain ordering of jobs is prescribed either by technological constraints or by externally imposed policy.

\section{PRACTICAL SITUATION}

Various practical situations occur in real life when the machines on which jobs are to be processed are planted at different places, the transportation time (which includes loading time, moving time and unloading time etc.) has a significant role in production concern. Further the priority of one job over other may be significant due to the relative importance of the jobs. It may be because of urgency or demand of its relative importance, the job block criteria becomes important. The concept of machines on rent is one of the latest. Renting enables saving working capital, gives option for having the equipment, and allows upgradation to new technology.

When one has got the assignments but does not have one's own machine or does not have enough money or does not want to take risk of investing huge amount of money to purchase machine. Under such circumstances, the machine has to be taken on rent in order to complete the assignments. In his starting career, we find a medical practitioner does not buy expensive machines say X-ray machine, Ultra Sound Machine, Rotating Triple Head Single Positron Emission Computed Tomography Scanner, Patient Monitoring Equipment, and Laboratory Equipment etc., but instead takes on rent. Rental of medical equipment is an affordable and quick solution for hospitals, nursing homes, physicians, which are presently constrained by the availability of limited funds due to the recent global economic recession.

\section{NOTATIONS}

$\begin{array}{ll}\mathrm{S} & \text { : Sequence of jobs } 1,2,3, \ldots, \mathrm{n} \\ \mathrm{M}_{\mathrm{j}} & \text { : Machine } \mathrm{j}, \mathrm{j}=1,2,3 \\ \mathrm{M} & \text { : Minimum makespan } \\ \mathrm{a}_{\mathrm{ij}} & \text { : Processing time of } \mathrm{i}^{\text {th }} \text { job on machine } \mathrm{M}_{\mathrm{j}} \\ \mathrm{p}_{\mathrm{ij}} & \text { : Probability associated to the processing time } \mathrm{a}_{\mathrm{ij}} \\ A_{i j} & : \text { Expected processing time of } \mathrm{i}^{\text {th }} \text { job on machine } \mathrm{M}_{\mathrm{j}} \\ \alpha & \text { : Equivalent job for job }- \text { block } \\ C_{i} & : \text { Rental cost of } i^{\text {th }} \text { machine }\end{array}$


$L_{j}(S) \quad$ : The latest time when machine $M_{j}$ is taken on rent for sequence $S$

$t_{i j}(S) \quad$ : Completion time of $i^{\text {th }}$ job of sequence $S$ on machine $M_{j}$

$t_{i j}^{\prime}(S)$ : Completion time of $i^{\text {th }}$ job of sequence $S$ on machine $M_{j}$ when machine $M_{j}$ start processing jobs at time $L_{j}(S)$

$T_{\mathrm{i}, \mathrm{j} \rightarrow \mathrm{k}} \quad$ : Transportation time of $\mathrm{i}^{\text {th }}$ job from $\mathrm{j}^{\text {th }}$ machine to $\mathrm{k}^{\text {th }}$ machine

$I_{i j}(S) \quad$ : Idle time of machine $M_{j}$ for job $i$ in the sequence $S$

$U_{j}(S)$ :Utilization time for which machine $M_{j}$ is required,

when $M_{\mathrm{j}}$ starts processing jobs at time $L_{j}(S)$

$R(S) \quad$ : Total rental cost for the sequence $S$ of all machine

\subsection{Definition}

Completion time of $i^{\text {th }}$ job on machine $M_{j}$ is denoted by $t_{i j}$ and is defined as

$$
\begin{aligned}
t_{i j} & =\max \left(t_{i-1, j}, t_{i, j-1}\right)+T_{i,(j-1) \rightarrow j}+a_{i j} \times p_{i j} \text { for } j \geq 2 . \\
& =\max \left(t_{i-1, j}, t_{i, j-1}\right)+T_{i,(j-1) \rightarrow j}+A_{i, j}
\end{aligned}
$$

where $A_{i, j}=$ expected processing time of $i^{\text {th }}$ job on machine $j$.

\subsection{Definition}

Completion time of $i^{t h}$ job on machine $M_{j}$ when $M_{j}$ starts processing jobs at time $L_{j}$ is denoted by $t_{i, j}$ and is defined as

$$
\begin{aligned}
& t_{i, j}^{\prime}=L_{j}+\sum_{k=1}^{i} A_{k, j}=\sum_{k=1}^{i} I_{k, j}+\sum_{k=1}^{i} A_{k, j} \\
& =\max \left(t_{i, j-1}, t_{i-1, j}^{\prime}\right)+A_{i, j}
\end{aligned}
$$

\section{RENTAL POLICY}

The machines will be taken on rent as and when they are required and are returned as and when they are no longer required i.e. the first machine will be taken on rent in the starting of the processing the jobs, $2^{\text {nd }}$ machine will be taken on rent at time when $1^{\text {st }}$ job is completed on $1^{\text {st }}$ machine and transported to $2^{\text {nd }}$ machine, $3^{\text {rd }}$ machine will be taken on rent at time when $1^{\text {st }}$ job is completed on the $2^{\text {nd }}$ machine and transported.

\section{THEOREM}

The processing of jobs on $\mathrm{M}_{3}$ at time $L_{3}=\sum_{i=1}^{n} I_{i, 3}$ keeps $\mathrm{t}_{\mathrm{n}, 3}$ unaltered.

Proof: Let $t_{n, 3}^{\prime}$ be the competition time of $\mathrm{i}^{\text {th }}$ job on machine $M_{3}$ when $M_{3}$ starts processing of jobs at time $L_{3}$. We shall prove the theorem with the help of Mathematical Induction.

$$
\text { Let } P(n): t_{n, 3}^{\prime}=t_{n, 3}
$$

Basic Step: For $\mathrm{n}=1$

$$
\begin{aligned}
t_{1,3}^{\prime} & =L_{3}+A_{1,3}=I_{1,3}+A_{1,3} \\
= & \left(A_{1,1}+\left(T_{1,1 \rightarrow 2}+A_{1,2}\right)+T_{1,2 \rightarrow 3}\right)+A_{l, 3}=t_{l, 3} .
\end{aligned}
$$

Therefore $\mathrm{P}(1)$ is true.

Induction Step: Let $\mathrm{P}(\mathrm{k})$ be true.

$$
\text { i.e. } t_{k, 3}^{\prime}=t_{k, 3} \text {. }
$$

Now, we shall show that $\mathrm{P}(\mathrm{k}+1)$ is also true.

$$
\text { i.e. } t_{k+1,3}^{\prime}=t_{k+1,3}
$$

But $\quad t_{k+1,3}^{\prime}=\max \left(t_{k+1,2}, t_{k, 3}^{\prime}\right)+T_{k+1,2 \rightarrow 3}+A_{k+1,3} \quad$ (As per Definition 2)

$$
\begin{aligned}
& \therefore t_{k+1,3}^{\prime}=\max \left(t_{k+1,2}, L_{3}+\sum_{i=1}^{k} A_{i, 3}\right)+T_{k+1,2 \rightarrow 3}+A_{k+1,3} \\
& =\max \left(t_{k+1,2}, \sum_{i=1}^{k+1} I_{1,3}+\sum_{i=1}^{k} A_{i, 3}\right)+T_{k+1,2 \rightarrow 3}+A_{k+1,3} \\
& =\max \left(t_{k+1,2}, \sum_{i=1}^{k} I_{1,3}+\sum_{i=1}^{k} A_{i, 3}+I_{k+1,3}\right)+T_{k+1,2 \rightarrow 3}+A_{k+1,3} \\
& =\max \left(t_{k+1,2}, t_{k, 3}+I_{k+1,3}\right)+T_{k+1,2 \rightarrow 3}+A_{k+1,3} \\
& =\max \left(t_{k+1,2}, t_{k, 3}+I_{k+1,3}\right)+T_{k+1,2 \rightarrow 3}+A_{k+1,3}
\end{aligned}
$$

(by assumption)

$$
\begin{aligned}
& \max \left(t_{k+1,2}, t_{k, 3}^{\prime}+\max \left(\left(t_{k+1,2}-t_{k, 3}\right), 0\right)\right)+T_{k+1,2 \rightarrow 3}+A_{k+1,3} \\
& =\max \left(t_{k+1,2}, t_{k, 3}\right)+T_{k+1,2 \rightarrow 3}+A_{k+1,3}=t_{k+1,3} \\
& \Rightarrow P(k+1) \text { is true. }
\end{aligned}
$$

Hence by principle of mathematical induction $\mathrm{P}(\mathrm{n})$ is true for all n, i.e. $t_{n, 3}^{\prime}=t_{n, 3}$.

\subsection{LEMMA}

If $M_{3}$ starts processing jobs at $L_{3}=\sum_{i=1}^{n} I_{i, 3}$ then

$$
\begin{aligned}
& \text { (i). } L_{3}>t_{1,2} \\
& \text { (ii). } t_{k+1,3}^{\prime} \geq t_{k, 2}, k>1 .
\end{aligned}
$$

\section{THEOREM}

The processing of jobs on $M_{2}$ at time $L_{2}=\min _{i \leq k \leq n}\left\{Y_{k}\right\}$ keeps total elapsed time unaltered where

$$
\begin{aligned}
& Y_{1}=L_{3}-A_{1,2}-T_{1,2 \rightarrow 3} \text { and } \\
& Y_{k}=t_{k-1,3}^{\prime}-\sum_{i=1}^{k} A_{i, 2}-\sum_{i=1}^{k} T_{i, 2 \rightarrow 3} ; k>1 .
\end{aligned}
$$

Proof: Since $L_{2}=\min _{i \leq k \leq n}\left\{Y_{k}\right\}=Y_{r}$ (say)

In particular for $\mathrm{k}=1$

$$
\begin{aligned}
& Y_{r} \leq Y_{1} \\
& \Rightarrow Y_{r}+A_{1,2}+T_{1,2 \rightarrow 3} \leq Y_{1}+A_{1,2}+T_{1,2 \rightarrow 3} \\
& \Rightarrow Y_{r}+A_{1,2}+T_{1,2 \rightarrow 3} \leq L_{3} \\
& \left(\because Y_{1}=L_{3}-A_{1,2}-T_{1,2 \rightarrow 3}\right)
\end{aligned}
$$

By Lemma 1; we have

$t_{1,2} \leq L_{3}$ 
Also, $t_{1,2}^{\prime}=\max \left(Y_{r}+A_{1,2}+T_{1,2 \rightarrow 3}, t_{1,2}\right)$

On combining, we get $t_{1,2}^{\prime} \leq L_{3}$

For k $>1$, As $Y_{r}=\min _{i \leq k \leq n}\left\{Y_{k}\right\}$

$\Rightarrow Y_{r} \leq Y_{k} ; \quad k=2,3 \ldots \ldots \ldots, n$

$\Rightarrow Y_{r}+\sum_{i=1}^{k} A_{i, 2}+\sum_{i=1}^{k} T_{i, 2 \rightarrow 3} \leq Y_{k}+\sum_{i=1}^{k} A_{i, 2}+\sum_{i=1}^{k} T_{i, 2 \rightarrow 3}$

$\Rightarrow Y_{r}+\sum_{i=1}^{k} A_{i, 2}+\sum_{i=1}^{k} T_{i, 2 \rightarrow 3} \leq t_{k-1,3}^{\prime}$

By Lemma 1; we have

$t_{k, 2} \leq t_{k-1,3}^{\prime}$

Also, $\quad t_{k, 2}^{\prime}=\max \left(Y_{r}+\sum_{i=1}^{k} A_{i, 2}+\sum_{i=1}^{k} T_{i, 2 \rightarrow 3}, t_{k, 2}\right)$

Using (3) and (4), we get $t_{k, 2}^{\prime} \leq t_{k-1,3}^{\prime}$

Taking $k=n$, we have

$t_{n, 2}^{\prime} \leq t_{n-1,3}^{\prime}$

Total time elapsed $=t_{n, 3}$

$=\max \left(t_{n, 2}^{\prime}, t_{n-1,3}^{\prime}\right)+A_{n, 3}+T_{n, 2 \rightarrow 3}$

$=t_{n-1,3}^{\prime}+A_{n, 3}+T_{n, 2 \rightarrow 3} \quad$ (using 5)

$=t_{n, 3}^{\prime}$.

Hence, the total time elapsed remains unaltered if $M_{2}$ starts processing jobs at time

\section{PROBLEM FORMULATION}

Let some job $i(i=1,2, \ldots \ldots \ldots, \mathrm{n})$ is to be processed on three machines $M_{j}(j=1,2,3)$ under the specified rental policy $\mathrm{P}$. Let $a_{i j}$ be the processing time of $i^{\text {th }}$ job on $j^{\text {th }}$ machine with probabilities $p_{i j}$. . Let $A_{i j}$ be the expected processing time of $i^{\text {th }}$ job on $j^{\text {th }}$ machine. Let $T_{\mathrm{i}, \mathrm{j} \rightarrow \mathrm{k}}$ be the transportation time of $\mathrm{i}^{\text {th }}$ job from $\mathrm{j}^{\text {th }}$ machine to $\mathrm{k}^{\mathrm{th}}$ machine. Let $\alpha=\left(i_{k}, i_{m}\right)$ be an equivalent job for job block in which job $i_{k}$ is given priority over job $i_{m}$. Take two job blocks $\alpha$ and $\beta$ such that block $\alpha$ consists of $m$ jobs out of $n$ jobs in which the order of jobs is fixed and $\beta$ consists of $r$ jobs out of $n$ in which order of jobs is arbitrary such that $m+r=n$. Let $\alpha \cap \beta=\varnothing$ i.e. the two job blocks $\alpha \& \beta$ form a disjoint set in the sense that the two blocks have no job in common. A string $S$ of job blocks $\alpha$ and $\beta$ is defined as $S=(\alpha, \beta)$. Our objective is to find an optimal sequence $S$ of the jobs which minimize the rental cost of all the three machines while minimizing total elapsed time.

Mathematically, the problem is stated as:

Minimize $U_{j}(S)$ and

Minimize $R(S)=\sum_{i=1}^{n} A_{i 1} \times C_{1}+U_{2}(S) \times C_{2}+\sum_{i=1}^{n} A_{i 3} \times C_{3}$

Subject to constraint: Rental Policy (P)
Our objective is to minimize rental cost while minimizing total elapsed time.

Table 1 the mathematical model of the problem in matrix form

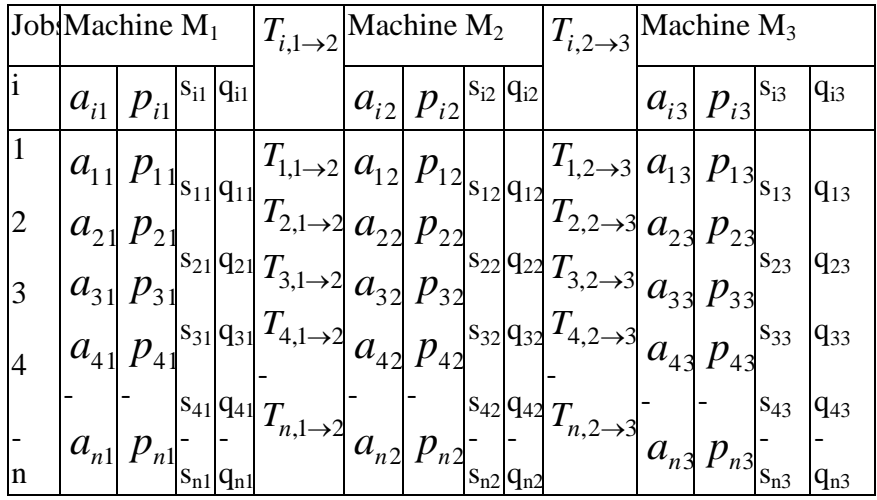

\section{ALGORITHM}

Step 1: Calculate the expected processing times $A_{i j}=a_{i j} \times p_{i j} \forall i, j=1,2,3$

Step 2: Check the structural condition

$$
\text { Either } \operatorname{Min}\left\{\mathrm{A}_{\mathrm{i} 1}+\mathrm{T}_{\mathrm{i}, 1 \rightarrow 2}\right\} \geq \operatorname{Max}\left\{\mathrm{A}_{\mathrm{i} 2}+\mathrm{T}_{\mathrm{i}, 1 \rightarrow 2}\right\}
$$
for all i

or $\operatorname{Min}\left\{\mathrm{A}_{\mathrm{i} 3}+\mathrm{T}_{\mathrm{i}, 2 \rightarrow 3}\right\} \geq \operatorname{Max}\left\{\mathrm{A}_{\mathrm{i} 2}+\mathrm{T}_{\mathrm{i}, 2 \rightarrow 3}\right\}$ or both

If the conditions are satisfied then go to step 3, else the data is not in the standard form.

Step 3: Introduce the two fictitious machines $\mathrm{G}$ and $\mathrm{H}$ with processing times $G_{i}$ and $H_{i}$ as

$G_{i}=A_{i 1}+T_{i, 1 \rightarrow 2}+A_{i 2}+T_{i, 2 \rightarrow 3}$ and

$H_{i}=A_{i 2}+T_{i, 1 \rightarrow 2}+A_{i 3}+T_{i, 2 \rightarrow 3}$ for all $i$.

Step 4: Take equivalent job $\alpha=\left(i_{k}, i_{m}\right)$ for the given job block $\left(i_{k}, i_{m}\right)$ and define its processing time on the lines of Maggu \& Das [9] defined as follows:

$G_{\alpha}=G_{k}+G_{m}-\min \left(G_{m}, H_{k}\right) \quad$ and $\quad H_{\alpha}=H_{k}+H_{m}-\min \left(G_{m}\right.$ , $\left.H_{k}\right)$

Step 5: Obtain the order of jobs in the job block $\beta$ in an optimal manner using Johnson's [7] technique by treating job block $\beta$ as sub flow shop scheduling problem of the main problem. Let $\beta^{\prime}$ be the new job block. Define its processing time $G_{\beta^{\prime}} \& H_{\beta^{\prime}}$ on the lines of Maggu \& Das [9] as defined in step 4.

Now, the given problem reduce into new problem replacing $\mathrm{m}$ jobs by job block $\alpha$ with processing times $G_{\alpha} \& H_{\alpha}$ on machine $\mathrm{G} \& \mathrm{H}$ respectively as defined in step 4 and $r$ jobs of job block $\beta$ by $\beta^{\prime}$ with processing times $G_{\beta^{\prime}} \& H_{\beta^{\prime}}$ on machine $\mathrm{G} \& \mathrm{H}$ respectively as defined in step 5 .

Table 2: The new problem

\begin{tabular}{|c|c|c|}
\hline Jobs $(i)$ & Machine $\mathrm{G}\left(G_{i}\right)$ & Machine $\mathrm{H}\left(H_{i}\right)$ \\
\hline$\alpha$ & $G_{\alpha}$ & $H_{\alpha}$ \\
\hline$\beta^{\prime}$ & $G_{\beta^{\prime}}$ & $H_{\beta}$, \\
\hline
\end{tabular}


Step 6: Let $S_{1}$ denote set of all the processing time $G_{i}$ when $G_{i} \leq H_{i}$ and let $\mathrm{S}_{2}$ denote the set of processing times which are not covered in set $S_{1}$. time subject to minimization of the total rental cost of the machines.

Solution: As per Step 1: The expected processing times for machines $\mathrm{M}_{1}, \mathrm{M}_{2}$ and $\mathrm{M}_{3}$ are

Step 7: Let $S_{1}^{\prime}$ denote a suboptimal sequence of jobs corresponding to non decreasing times in set $S_{1} \&$ let $S_{2}^{\prime}$ denote a suboptimal sequence of jobs co

Step 8: The augmented ordered sequence $S=\left(S_{1}^{\prime}, S_{2}^{\prime}\right)$ gives optimal sequence for processing the jobs for the original problem.

Step 9: Prepare In - Out tables for sequence $S$ and compute total elapsed time $\mathrm{t}_{\mathrm{n} 3}(S)$

Step 10: Compute latest time $L_{3}$ for machine $M_{3}$ for sequence $S$ as

$$
L_{3}(S)=t_{n 3}(S)-\sum_{i=1}^{n} A_{i 3}
$$

Step 11: For the sequence $S$, compute

$t_{n 2}(S)$

$Y_{1}(S)=L_{3}(S)-A_{1,2}(S)-T_{1,2 \rightarrow 3}$

$Y_{q}(S)=L_{3}(S)-\sum_{i=1}^{q} A_{i 2}(S)-\sum_{i=1}^{q} T_{i, 2 \rightarrow 3}+\sum_{i=1}^{q-1} A_{i, 3}+\sum_{i=1}^{q-1} T_{i, 1 \rightarrow 2} ; q=2,3, \ldots \ldots, n$

$L_{2}(S)=\min _{1 \leq q \leq n}\left\{Y_{q}(S)\right\}$

$U_{2}(S)=t_{n 2}(S)-L_{2}(S)$.

Step 12: Compute total rental cost of all the three machines for sequence $S$ as:

$$
R(S)=\sum_{i=1}^{n} A_{i 1} \times C_{1}+U_{2}(S) \times C_{2}+\sum_{i=1}^{n} A_{i 3} \times C_{3}
$$

\section{NUMERICAL ILLUSTRATION}

Consider 5 jobs, 3 machine flow shop problem with processing time associated with their respective probabilities and transportation time as given in table and jobs 2 and 5 are processed as a group job $(2,5)$. The rental cost per unit time for machines $M_{1}, M_{2}$ and $M_{3}$ are 4 units, 6 units and 8 units respectively, under the specified rental policy $\mathrm{P}$.

Table 3: Three machines with processing and

\begin{tabular}{|c|c|c|c|c|c|c|c|c|}
\hline Jobs & \multicolumn{2}{|c|}{$\begin{array}{l}\text { Machine } \\
M_{1}\end{array}$} & \multirow[t]{2}{*}{$T_{i, 1 \rightarrow 2}$} & \multicolumn{2}{|c|}{$\begin{array}{l}\text { Machine } \\
\mathrm{M}_{2}\end{array}$} & \multirow[t]{2}{*}{$T_{i, 2 \rightarrow 3}$} & \multicolumn{2}{|c|}{$\begin{array}{l}\text { Machine } \\
\mathrm{M}_{3}\end{array}$} \\
\hline i & $a_{i 1}$ & $\mathrm{p}_{\mathrm{i} 1}$ & & $a_{i 2}$ & $\mathrm{p}_{\mathrm{i} 2}$ & & $a_{i 3}$ & $\mathrm{p}_{\mathrm{i} 3}$ \\
\hline 1 & 27 & 0.2 & 2 & 7 & 0.3 & 2 & 17 & 0.2 \\
\hline 2 & 30 & 0.2 & 2 & 20 & 0.2 & 1 & 18 & 0.3 \\
\hline 3 & 42 & 0.2 & 2 & 22 & 0.2 & 2 & 12 & 0.2 \\
\hline 4 & 24 & 0.2 & 3 & 24 & 0.1 & 3 & 23 & 0.1 \\
\hline 5 & 22 & 0.2 & 4 & 9 & 0.2 & 4 & 25 & 0.2 \\
\hline
\end{tabular}
transportation time

Our objective is to obtain an optimal schedule for above said problem to minimize the total production time / total elapsed
Table 4: The expected processing times for machines

\begin{tabular}{|c|c|c|c|c|c|}
\hline Jobs & $A_{i 1}$ & $T_{i, 1 \rightarrow 2}$ & $A_{i 2}$ & $T_{i, 2 \rightarrow 3}$ & $A_{i 3}$ \\
\hline 1 & 5.4 & 2 & 2.1 & 2 & 3.4 \\
\hline 2 & 6.0 & 2 & 4.0 & 1 & 5.4 \\
\hline 3 & 8.4 & 2 & 4.4 & 2 & 2.4 \\
\hline 4 & 4.8 & 3 & 2.4 & 3 & 2.3 \\
\hline 5 & 4.4 & 4 & 1.8 & 4 & 5.0 \\
\hline
\end{tabular}

As per step 2 \& 3: The expected processing times $\mathrm{G}_{\mathrm{i}}$ and $\mathrm{H}_{\mathrm{i}}$ for two fictitious machines

Table 5: Expected processing times for two fictitious machines $\mathbf{G} \& \mathbf{H}$

\begin{tabular}{|c|l|l|}
\hline Jobs & $\mathrm{G}_{\mathrm{i}}$ & $\mathrm{H}_{\mathrm{i}}$ \\
\hline 1 & 11.5 & 9.5 \\
\hline 2 & 13.0 & 12.4 \\
\hline 3 & 16.8 & 10.8 \\
\hline 4 & 13.2 & 10.7 \\
\hline 5 & 14.2 & 14.8 \\
\hline
\end{tabular}

As per step 4:Here $\alpha=(2,5)$

Therefore, $G_{\alpha}=13.0+14.2-12.4=14.8$ and $H_{\alpha}=12.4+$ $14.8-12.4=14.8$

As per step 5: Here $\beta=(1,3,4)$

Now, using Johnson [1] technique by treating job block $\beta$ as sub flow shop scheduling problem of the main problem. Let $\beta^{\prime}$ be the new job block. Here we get $\beta^{\prime}=(3,4,1)$

Also $\beta^{\prime}=(3,4,1)=((3,4), 1)=\left(\alpha^{\prime}, 1\right)$, where $\alpha^{\prime}=(3$, 4)

$G_{\beta^{\prime}}=19.2+11.5-10.7=20$ and $H_{\beta}^{\prime}=10.7+9.5-$ $10.7=9.5$

As per step 6: $S_{1}=14.8, S_{2}=20$

As per step 7: $\mathrm{S}_{1}^{\prime}=\alpha, \mathrm{S}_{2}^{\prime}=\beta^{\prime}$

As per step 8: Optimal sequence is $S=2-5-3-4-1$

As per step 9: The In - Out flow table for the optimal sequence $\mathrm{S}$ is

\begin{tabular}{|c|c|c|c|c|c|}
\hline $\mathrm{J}$ & $\mathrm{M}_{1}$ & $T_{i, 1 \rightarrow 2}$ & $\mathrm{M}_{2}$ & $T_{i, 2 \rightarrow 3}$ & $\mathrm{M}_{3}$ \\
\hline i & In - Out & & In-Out & & In - Out \\
\hline 2 & $0-6.0$ & 2 & $8.0-12.0$ & 1 & $13.0-18.4$ \\
\hline
\end{tabular}

Table 6: The In-Out table 


\begin{tabular}{|c|c|c|c|c|c|}
\hline 5 & $6.0-10.4$ & 4 & $14.4-16.2$ & 4 & $20.2-25.2$ \\
\hline 3 & $10.4-18.8$ & 2 & $20.8-25.2$ & 2 & $27.2-29.6$ \\
\hline 4 & $18.8-23.6$ & 3 & $26.6-29.0$ & 3 & $32.0-34.3$ \\
\hline 1 & $23.6-29$ & 2 & $31.0-33.1$ & 2 & $35.1-38.5$ \\
\hline
\end{tabular}

Total elapsed time $t_{\mathrm{n} 3}(\mathrm{~S})=38.5$ units

As per Step 10: $L_{3}(S)=t_{n 3}(S)-\sum_{i=1}^{n} A_{i, 3}(S)=38.5-18.5$ $=20$ units

As per Step 11: For sequence S, we have

$$
\begin{aligned}
& Y_{1}=20-4.0-1=15 \\
& Y_{2}=20-10.8+7.4=16.6 \\
& Y_{3}=20-17.2+16.4=19.2 \\
& Y_{4}=20-22.6+20.8=18.2 \\
& Y_{5}=20-26.7+26.1=19.4 \\
& L_{2}(S)=\operatorname{Min}\left\{Y_{k}\right\}=15 \\
& U_{2}(S)=t_{n 2}(S)-L_{2}(S)=33.1-15=18.1
\end{aligned}
$$

\begin{tabular}{|c|c|c|c|c|c|}
\hline $\mathrm{J}$ & $\mathrm{M}_{1}$ & $T_{i, 1 \rightarrow 2}$ & $\mathrm{M}_{2}$ & $T_{i, 2 \rightarrow 3}$ & $\mathrm{M}_{3}$ \\
\hline i & In-Out & & In - Out & & In - Out \\
\hline 2 & $0-6.0$ & 2 & $15.0-19.0$ & 1 & $20.0-25.4$ \\
\hline 5 & $6.0-10.4$ & 4 & $19.0-20.8$ & 4 & $25.4-30.4$ \\
\hline 3 & $10.4-18.8$ & 2 & $20.8-25.2$ & 2 & $30.4-32.8$ \\
\hline 4 & $18.8-23.6$ & 3 & $26.6-29.0$ & 3 & $32.8-35.1$ \\
\hline 1 & $23.6-29.0$ & 2 & $31.0-33.1$ & 2 & $35.1-38.5$ \\
\hline
\end{tabular}

The new reduced Bi-objective In - Out table is

The latest possible time at which machine $\mathrm{M}_{2}$ should be taken on rent $=\mathrm{L}_{2}(\mathrm{~S})=15$ units.

Also, utilization time of machine $\mathrm{M}_{2}=\mathrm{U}_{2}(\mathrm{~S})=18.1$ units.

Total Minimum rental cost $=$

$$
\begin{aligned}
R(S) & =\sum_{i=1}^{n} A_{i 1} \times C_{1}+U_{2}(S) \times C_{2}+\sum_{i=1}^{n} A_{i 3} \times C_{3} \\
& =372.6 \text { Units. }
\end{aligned}
$$

\section{APPENDIX}

\section{Programme}

\#include<iostream.h>

\#include<stdio.h>

\#include<conio.h $>$

\#include<process.h>

int n,e;

float a1[16],b1[16],c1[16],g[16],h[16],T12[16],T23[16];

float macha[16],machb[16],machc[16];

float cost_a,cost_b,cost_c,cost;

int $\mathrm{f}=1$;

float minval,minv, $\operatorname{maxv} 1[16], \max 2[16]$;

int group[16];//variables to store two job blocks int $g g=0$;

float gcal,hcal;

float gbeta $=0.0$,hbeta $=0.0$; float galfa $=0.0$, halfa $=0.0$ char s1[5]; char s2[5];

void ghcal(int k,int m)

float minv;

if $(\mathrm{g}[\mathrm{m}]>\mathrm{h}[\mathrm{k}])$

$\operatorname{minv}=\mathrm{h}[\mathrm{k}]$

else

$\operatorname{minv}=\mathrm{g}[\mathrm{m}] ; \mathrm{gcal}=\mathrm{g}[\mathrm{k}]+\mathrm{g}[\mathrm{m}]-\operatorname{minv} ; \mathrm{hcal}=\mathrm{h}[\mathrm{k}]+\mathrm{h}[\mathrm{m}]-\operatorname{minv}$ //return(c);

\}

void main(

clrscr();

int a[16],b[16],c[16],j[16];float p[16],q[16],r[16];

cout $<<$ "How many Jobs $(<=15)$ : "; cin $>>n$;

if $(\mathrm{n}<1 \| \mathrm{n}>15)$

cout $<<$ endl $<<$ "Wrong input, No. of jobs should be less than 15..In Exitting";

getch();exit(0);

for(int $\mathrm{i}=1 ; \mathrm{i}<=\mathrm{n} ; \mathrm{i}++)$

\{

$\mathrm{j}[\mathrm{i}]=\mathrm{i}$;

cout $<<" \backslash$ nEnter the processing time and its probability of " $<<i<<"$ job for machine A and Transportation time from Machine A to B :

"; $\operatorname{cin}>>\mathrm{a}[\mathrm{i}]>>\mathrm{p}[\mathrm{i}]>>\mathrm{T} 12[\mathrm{i}]$ cout $<<" \mid$ nEnter the processing time and its probability of " $<<i<<"$ job for machine B and Transportation time from Machine $\mathrm{B}$ to $\mathrm{C}$ : "; cin>>b[i] >>q[i] >>T23[i];

cout $<<"$ InEnter the processing time and its probability of " $<<i<<"$ job for machine $\mathrm{C}$ : ";

cin $>>c[i]>>r[i] ;$

a1 $[i]=a[i] * p[i] ; b 1[i]=b[i] * q[i] ; c 1[i]=c[i] * r[i] ;$

cout $<<" \backslash$ EnEnter the rental cost of Machine M1:";cin >>cost_a; cout $<<" \mid$ nEnter the rental cost of Machine M2:"; $\operatorname{cin}>>$ cost b; cout $<<" \mid$ nEnter the rental cost of Machine M3:";cin >>cost_c; cout $<<$ endl $<<$ Expected processing time of machine A, B and C: $\ln "$;

for $(\mathrm{i}=1 ; \mathrm{i}<=\mathrm{n} ; \mathrm{i}++)$

cout $<<\mathrm{j}[\mathrm{i}]<<"|\mathrm{t} "<<\mathrm{a} 1[\mathrm{i}]<<"| \mathrm{t} "<<\mathrm{b} 1[\mathrm{i}]<<"|\mathrm{t} "<<\mathrm{c} 1[\mathrm{i}]<<"| \mathrm{t} " ;$ cou $\mathrm{t}<<$ endl;

\}

//Function for two ficticious machine $\mathrm{G}$ and $\mathrm{H}$

//Finding smallest in a1

float minal;

$\operatorname{mina} 1=\mathrm{a} 1[1]+\mathrm{T} 12[1]$

for $(\mathrm{i}=2 ; \mathrm{i}<\mathrm{n} ; \mathrm{i}++)$

if (a1 $[\mathrm{i}]+\mathrm{T} 12[\mathrm{i}]<\operatorname{mina} 1)$ mina $1=\mathrm{a} 1[\mathrm{i}]+\mathrm{T} 12[\mathrm{i}]$

//For finding largest in b1

float $\operatorname{maxb} 1 ; \operatorname{maxb} 1=\mathrm{b} 1[1]+\mathrm{T} 23[1]$;

for $(\mathrm{i}=2 ; \mathrm{i}<\mathrm{n} ; \mathrm{i}++)$

if $(\mathrm{b} 1[\mathrm{i}]+\mathrm{T} 23[\mathrm{i}]>\operatorname{maxb} 1)$ $\operatorname{maxb} 1=\mathrm{b} 1[\mathrm{i}]+\mathrm{T} 23[\mathrm{i}]$ 
\}

//Finding smallest in c1

float minc1;

$\operatorname{minc} 1=\mathrm{c} 1[1]+\mathrm{T} 23[1]$

for $(\mathrm{i}=2 ; \mathrm{i}<\mathrm{n} ; \mathrm{i}++)$

\{

if $(\mathrm{c} 1[\mathrm{i}]+\mathrm{T} 23[\mathrm{i}]<\operatorname{minc} 1)$

$\operatorname{minc} 1=\mathrm{c} 1[\mathrm{i}]+\mathrm{T} 23[\mathrm{i}]$;

\}

if $(\operatorname{mina} 1>=\operatorname{maxb} 1 \| \operatorname{minc} 1>=\operatorname{maxb} 1)$

\{

for $(\mathrm{i}=1 ; \mathrm{i}<=\mathrm{n} ; \mathrm{i}++)$

\{

$\mathrm{g}[\mathrm{i}]=\mathrm{a} 1[\mathrm{i}]+\mathrm{T} 12[\mathrm{i}]+\mathrm{b} 1[\mathrm{i}]+\mathrm{T} 23[\mathrm{i}]$;

$\mathrm{h}[\mathrm{i}]=\mathrm{T} 12[\mathrm{i}]+\mathrm{b} 1[\mathrm{i}]+\mathrm{T} 23[\mathrm{i}]+\mathrm{c} 1[\mathrm{i}]$;

\}

\}

else

\{

cout $<<"$ "In data is not in Standard

Form...InExitting";getch(); exit(0);

\}

cout $<<$ endl<<"Expected processing time for two fictious

machines $\mathrm{G}$ and $\mathrm{H}$ : $\backslash n "$;

for $(\mathrm{i}=1 ; \mathrm{i}<=\mathrm{n} ; \mathrm{i}++)$

\{

cout $<<$ endl; cout $<<\mathrm{j}[\mathrm{i}]<<"|\mathrm{t} "<<\mathrm{g}[\mathrm{i}]<<"| \mathrm{t} "<<\mathrm{h}[\mathrm{i}] ;$ cout $<<$ endl;

\}

cout $<<" \backslash$ nEnter the number of fixed jobs in job block alpha

$<="<<\mathrm{n}<<": "$; $\operatorname{cin}>>\mathrm{e}$;

cout $<<"$ InEnter the fixed job blocks $("<<\mathrm{e}<<"$ numbers from

1 to $"<<\mathrm{n}<<")$ alpha : ";

for(int $\mathrm{y}=1 ; \mathrm{y}<=\mathrm{e} ; \mathrm{y}++)$

\{

cin $>>$ group $[y]$;

\}

cout $<<" \mid$ nEnter the jobs having disjoint job block ( numbers

from 1 to $"<<\mathrm{n}<<"$ other

than the fixed job block) beta:";

for $($ int $\mathrm{u}=\mathrm{e}+1 ; \mathrm{u}<=\mathrm{n} ; \mathrm{u}++)$

\{

cin $>$ group $[\mathrm{u}]$;

\}

float btj[16],btg[16],bth[16];

cout $<<$ "Expected processing time for two fictious machines $\mathrm{G}$

and $\mathrm{H}$ for Beta: $\ln "$;

for $(\mathrm{i}=1, \mathrm{u}=\mathrm{e}+1 ; \mathrm{u}<=\mathrm{n} ; \mathrm{i}++, \mathrm{u}++)$

\{

btj[i]=group $[\mathrm{u}] ; \operatorname{btg}[\mathrm{i}]=\mathrm{g}[\operatorname{group}[\mathrm{u}]] ; \mathrm{bth}[\mathrm{i}]=\mathrm{h}[\operatorname{group}[\mathrm{u}]]$;

cout $<<$ endl $<<$ btj $[\mathrm{i}]<<" \mid \mathrm{t} "<<$ btg $[\mathrm{i}]<<" \mid \mathrm{t} "<<$ bth $[\mathrm{i}]$;

\}

float mingh[16];

char $\operatorname{ch}[16]$;

for $(\mathrm{i}=1 ; \mathrm{i}<=\mathrm{n}-\mathrm{e} ; \mathrm{i}++)$

\{

if $(b \operatorname{tg}[\mathrm{i}]<\mathrm{bth}[\mathrm{i}])$

\{

$\operatorname{mingh}[\mathrm{i}]=\mathrm{btg}[\mathrm{i}]$;

$\operatorname{ch}[\mathrm{i}]=$ 'g';

\}

else

\{

$\operatorname{mingh}[\mathrm{i}]=\mathrm{bth}[\mathrm{i}]$;

$\operatorname{ch}[\mathrm{i}]=$ 'h';

\}

\}

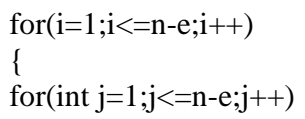




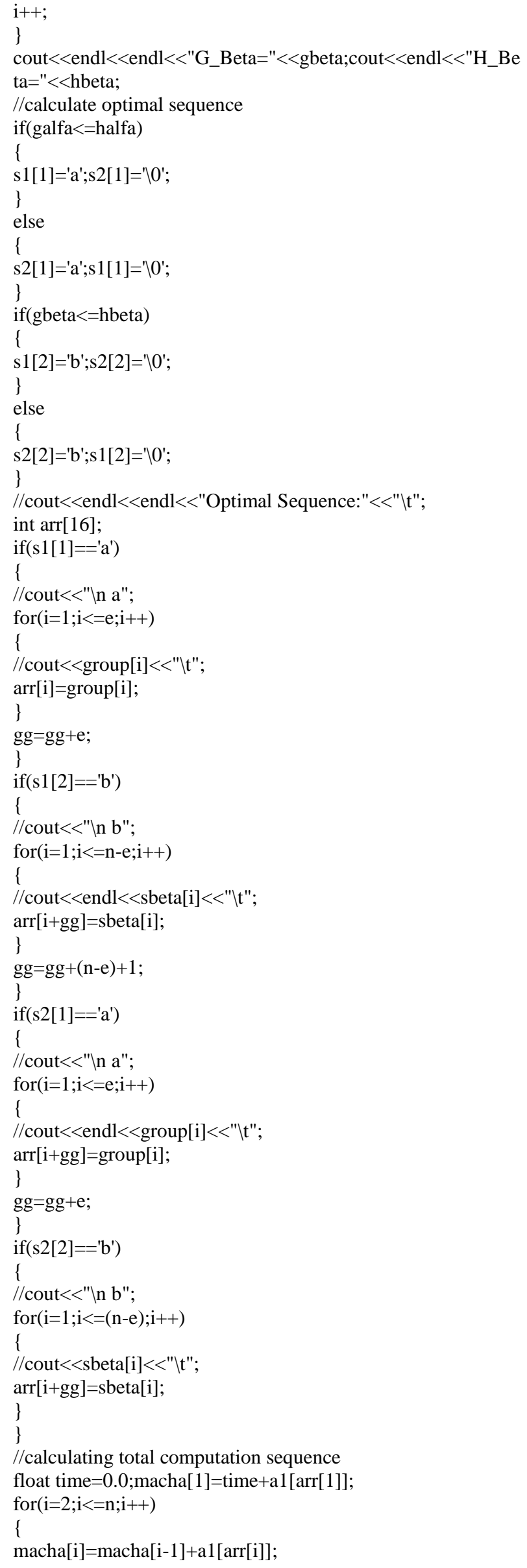

\} $\operatorname{machb}[1]=\operatorname{macha}[1]+\mathrm{b} 1[\operatorname{arr}[1]]+\mathrm{T} 12[\operatorname{arr}[1]] ;$ 


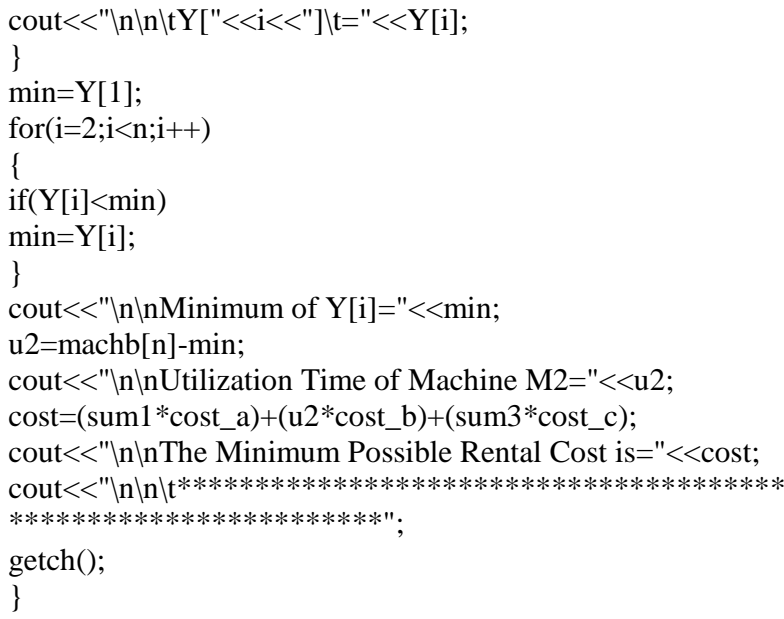

\section{REFERENCES}

[1] Ahmad Pour Darvish Heydari, "On flow shop scheduling problem with processing of jobs in a string of disjoint job blocks: fixed order jobs and arbitrary order jobs", JISSOR, XXIV, 2003, 39- 43.

[2] A.B. Chandramouli, "Heuristic Approach for n-job,3machine flow shop scheduling problem involving transportation time, breakdown interval and weights of jobs", Mathematical and Computational Applications.10(2), 2005, 301-305.

[3] P.Dileepan and T.Sen, "Bicriteria state scheduling research for a single machine", Omega, 16, 1988, 53-59.

[4] D.Gupta, S. Sharma, Seema and Shefali, "Bicriteria in $n$ $\times 2$ flow shop scheduling under specified rental policy ,processing time and setup time each associated with probabilities including job-block", Industrial Engineering Letter.1(1), 2011, $1-12$.

[5] D.Gupta, S. Sharma and Seema, "Bicriteria in $\mathrm{n} \times 3$ flow shop scheduling under specified rental policy, processing time associated with probabilities including transportation time and job block criteria", Mathematical Modelling and Theory. 1(2), 2011, 7-18.

[6] D. Gupta,S. Sharma S.\& N. Gulati, " $n \times 3$ flow shop production schedule, processing time, setup time each associated with probabilities along with jobs in string of disjoint job-blocks", Antartica J. Math.8(5), 2011, 443 457.

[7] S.M. Johnson. 1954. Optimal two and three stage production schedule with set up times included, Naval Research Logistics Quart. 1 (1954), 61-68.

[8] A. Khodadadi, "Development of a new heuristic for three machines flow-shop scheduling problem with transportation time of jobs", World Applied Sciences Journal. 5(5), 2008, 598-601.

[9] P.L. Maggu and G. Das, "Equivalent jobs for job block in job scheduling", Opsearch, 14(4), 1977, 277-281.

[10] L. Narian \& P.C. Bagga, "Minimizing hiring cost of machines in $\mathrm{n} \times$ 3flow shop problem", XXXI Annual ORSI Convention and International Conference on Operation Research and Industry, 1988, Agra[India].

[11] P.Pandian and P.Rajendran, "Solving constrained flowshop scheduling problems with three machines", Int. J. Contemp. Math. Sciences. 5(19), 2010, 921-929.

[12] R.D. Smith \& R.A. Dudek, "A general algorithm for solution of the N-job, M-machine scheduling problem", Opn. Res., 15(1), 1967, 71-82.

[13] W.E. Smith. 1967. Various optimizers for single stage production, Naval Research Logistics.3 (1967), 59-66.

[14] T. Sen and S.K. Gupta, "A branch and bound procedure to solve a bicriteria scheduling problem", AIIE Trans., $15,1983,84-88$.

[15] T.P. Singh, “On n x 2 flow shop problem involving job block, transportation times \& break- down machine times", PAMS XXI, 1985, 1-2.

[16] L.N.Van Wassenhove and L.F. Gelders, "Solving a bicriteria scheduling problem", AIIE Trans., 15, 1980, 84-88.

[17] L.N.Van Wassenhove and K.R. Baker, " A bicriteria approach to time/cost trade-offs in sequencing", EJOR, $11,1982,48-54$. 